\title{
KAJIAN TINGKAT TUNGGAKAN KREDIT SUB SEKTOR PERKEBUNAN PADA BANK RAKYAT INDONESIA UNIT PASAR RENGAS KABUPATEN BATANGHARI PROPINSI JAMBI
}

\author{
(PLANTATION SUB-SECTOR LOAN ARREARS LEVEL ASSESSMENT \\ IN THE BANK RAKYAT INDONESIA RENGAS MARKET UNIT \\ DISTRICT OF BATANGHARI JAMBI PROVINCE)
}

\author{
Febrinarni dan Reflis \\ Jurusan Sosial Ekonomi Pertanian, Fakultas Pertanian Universitas Bengkulu
}

\begin{abstract}
This research is aimed at assessing the Agriculture Sector Loan Arrears in BRI unit Pasar Rengas District of Batanghari and to analyze their determinant factors. Respondents were purposively selected as many as 69 people that is 50\% of 137 populations who applied for credit in the period from July to December 2009 to BRI unit Pasar Rengas District of Batanghari. Data were analysed using descriptive method while chi-square formula and the contingency coefficient formula are used to determine relationship between independent and dependent variables. The results of this study indicate that the level of customer credit arrears level at PT. BRI unit Pasar Rengas categorised as the high category, and the factors associated with the level of loan arrears are motivation, the number of family, loan experience, and revenue. Formal education and collaterals correlated significantly with the level of customer credit arrears.
\end{abstract}

Keywords: Loan Arrears, Plantation, Influenced Factors

\section{PENDAHULUAN}

Dilihat dari segi jumlah penduduk dan lahan budidaya pertanian Kabupaten Batanghari merupakan daerah pertanian. Kabupaten Batang Hari merupakan salah satu kabupaten di Propinsi Jambi, dengan luas wilayah mencapai 5.180,35 $\mathrm{Km}^{2}$ dan berpenduduk 191.727 jiwa, meliputi 8 Kecamatan (BPS, 2000). Pembangunan pertanian menjadi perhatian yang serius bagi pemerintah daerah untuk meningkatkan kesejahteraan dan kemandirian masyarakat, khususnya masyarakat tani.

Peranan pertanian sebagai sektor andalan dalam pembangunan ekonomi bangsa sudah tidak bisa diragukan lagi. Selama tiga dasawarsa, sektor pertanian telah berhasil memberikan kontribusi yang dominan dalam penyerapan tenaga 
kerja (45\%), sumbangan terhadap produk domestik bruto (PDB) nasional (18\%), serta tercapainya swasembada beras pada tahun 1984. Sebaliknya jika peran sektor pertanian mulai ditinggalkan maka pundi perekonomian nasional mulai rapuh. Hal ini terbukti ketika mulai tahun 1990 Indonesia mengimpor beras terbesar saat krisis ekonomi yaitu sebesar 5,78 ton (Nuhung, 2000)

Ketangguhan peran sektor pertanian terbukti saat menjadi penyelamat perekonomian nasional ketika bangsa Indonesia dilanda krisis global. Pengalaman saat krisis menunjukan bahwa penyerapan tenaga kerja oleh sektor di luar pertanian menurun, namun pada priode yang sama penyerapan tenaga pertanian justru naik. Selama krisis global dewasa ini, sektor pertanian ternyata masih mampu menyesuaikan diri terhadap krisis global. Sebaliknya, sub sektor industri banyak yang sudah gulung tikar. Akibatnya, kebijaksanaan pemerintah sebelumnya yang memprioritaskan pemberian kredit terhadap pengusaha besar yang ternyata pengembaliannya macet sehingga pemerintah mengeluarkan kredit yang cukup besar.

Pada umumnya, petani mendapatkan uang tunai sebagai modal usahanya dari hasil penjualan produk, menjual harta .kekayaan, mengambil tabungan, upah kerja, dan lain-lain. Namun jika modal-modal tersebut tidak mencukupi, maka petani atau nasabah mendapatkan penambahan modal melalui pinjaman atau kredit yang didapatkankan dari berbagai sumber. Sumber-sumber keuangan tersebut digolongkan menjadi sumber informal, family, tetangga, tengkulak,dan lain-lain. Selain itu juga adanya sumber keuangan formal seperti koperasi, perusahaan negara berupa penggadaian dan lembaga perbankan (Sinungun, 1987).

Lembaga perbankan (Bank) merupakan salah satu institusi yang memiliki peranan vital dalam perekonomian nasional, hal ini juga berkaitan dengan fungsi utama bank sebagai lembaga intermediary yang di satu sisi menghimpun dana dari masyarakat dan di sisi lain menyalurkan dana tersebut kepada kelompok masyarakat yang memerlukan dana (pasal 3 UU Perbankan). Penyaluran atau penyediaan dana dari Bank yang berupa pemberian kredit sangatlah penting dalam mendorong berputarnya roda perekonomian nasional, hal ini dikarenakan dengan pemberian kredit tersebut dapat dimanfaatkan untuk melakukan kegiatan-kegiatan produktif oleh masyarakat atau pelaku ekonomi (Kasmir, 2002)

Salah satu lembaga perbankan yang mempunyai jaringan terluas yang jangkaunnya sampai ke daerah pedesaan adalah Bank Rakyat Indonesia (BRI). Hal ini dikarenakan BRI mempunyai kantor-kantor unit yang dapat melayani ataupun memberikan fasilitas kredit kepada masyarakat daerah pedesaan khususnya para petani. Salah satu kredit yang diluncurkan guna mendukung pengembangan program pada sektor pertanian, adalah kredit peminjaman modal. Kredit ini dimaksudkan untuk membantu petani yang belum mampu membiayai sendiri usaha taninya dan diberi modal.

Di kecamatan Muaro Sebo Ulu hanya ada satu kantor BRI unit, yang mana mempunyai tugas untuk melayani ataupun memberikan pinjaman berupa kredit kepada masyarakat yang membutuhkan. Namun, BRI Unit Pasar Rengas 
mempunyai cakupan wilayah kerja yang cukup luas yang terdiri dari dua kecamatan yaitu kecamatan Mersam dan Kecamatan Maro Sebo Ulu, dimana pada kecamatan Mersam terdapat tiga Desa dan pada kecamatan Maro Sebo Ulu terdapat 12 desa. Pada kedua kecamatan tersebut rata-rata masyarakatnya bermata pencaharian sebagai petani atau pengusaha sektor pertanian. Selain itu juga, di daerah ini terdapat banyak sekali potensi-potensi sektor pertanian yang dapat diusahakan, seperti kopi, duku, jagung, ternak ayam, ikan, dan lain-lain. Dimana semua ini sangat membutuhkan modal dalam melakukan dan mengembangkan usahanya. Selain itu, berdasarkan informasi dari Cabang BRI Muaro Bulian, bahwa Bank di Unit Pasar Rengas tercatat sebagai Bank yang memiliki sangat banyak nasabah yang bermasalah pada kreditnya, dibandingkan dengan unit-unit BRI yang ada di kabupaten Batang Hari Jambi .

Dalam perjalannannya, PT. BRI Unit Pasar Rengas mengalami permasalahan dalam pemberian kredit yakni, sulitnya nasabah dalam melunasi angsuran pinjamannya, Permasalahan ini juga didukung dengan keadaan perekonomian yang mengalami krisis global dimana harga produk pertanian menurun sangat drastis, yang dampaknya sangat dirasakan langsung oleh petani maupun pengusaha di sektor pertanian. Dengan tanda-tanda terdapatnya penurunan harga produk-produk pertanian yang drastis yang berakibat pada tingkat penerimaan yang menurun. Hal ini juga akan mempengaruhi nasabah dalam melakukan pembayaran angsuran kepada pihak bank. Berangkat dari latar belakang ini, penelitian ini bertujuan untuk mengkaji tunggakan kredit sektor pertanian yang ada di BRI Unit Pasar Rengas Provinsi Jambi dan menganalisis faktor-faktor yang berhubungan dengan tingkat tunggakan kredit sektor pertanian di BRI Unit Pasar Rengas Provinsi Jambi.

\section{METODE PENELITIAN}

Penentuan lokasi penelitian dilakukan dengan sengaja (purposive) dengan pertimbangan bahwa di Bank Rakyat Indonesia Unit Pasar Rengas Jambi. Bank ini merupakan salah satu perusahaan yang bergerak dibidang perekonomian yang bisa meningkatkan produksi usaha pertanian khususnya pada petani sawit dan karet yang menunggak pinjaman pada Juli sampai Desember 2009. Populasi pada penelitian ini adalah seluruh nasabah Bank Rakyat Indonesia Unit Pasar Rengas yang menunggak kredit pada sektor pertanian. Penentuan responden dilakukan secara sengaja dari 12 desa yang berada di sekitar kawasan BRI Unit Pasar Rengas. Penentuan jumlah sampel dalam penelitian ini ditentukan sebanyak 50\% dari populasi yang menunggak kredit pada periode JuliDesember 2009. Teknik pemilihan responden dilakukan secara sengaja pada saat petugas BRI melakukan kunjungan kepada pihak nasabah yang menunggak yang selanjutnya dilakukan wawancara.

Metode analisis yang digunakan adalah uji statistik Chi Kuadrat (Siegel, 1992):

14 | Febrinarni, Reflis. Kajian Tingkat Tunggakan Kredit ... 


$$
X^{2}=\frac{\sum \boldsymbol{f}_{0}-f_{e}^{2}}{f_{e}}
$$

dimana : $\mathrm{X}^{2}=$ chi kuadrat, fo $=$ frekuensi yang diperoleh, fe = frekuensi yang diharapkan dalam sampel sebagai pencerminan dari frekuensi yang diharapkan.

Frekuensi yang diharapkan (fe) dihitung dari jumlah kategori variabel yang mempengaruhi tunggakan kredit dengan golongan dari pernyataan terhadap responden (jawaban responden) tentang perasaannya terhadap pertanyaan yang dijadikan acuan (lihat konsep dan pengukuran variabel) dibagi total sampel dengan rumus sebagai berikut:

$$
\mathrm{f}_{\mathrm{e}}=\frac{\mathrm{nk} \times \mathrm{nb}}{\mathrm{N}}
$$

dimana : $n k=$ jumlah ferkuensi yang diperoleh dalam kolom $(2$ kolom $), n b=$ jumlah frekuensi yang diperoleh dalam baris ( 2 baris), dan $\mathrm{N}=$ jumlah seluruh sampel.

\section{HASIL DAN PEMBAHASAN}

\section{Karakteristik Nasabah}

Karakteristik Nasabah Bank BRI meliputi: pendidikan formal, motivasi nasabah, jumlah tanggungan keluarga, pengalaman pinjaman, besar agunan, dan penerimaan. Untuk lebih jelasnya karakteristik responden dapat dilihat pada Tabel 1.

Pendidikan nasabah bervariasi dari yang tidak tamat SD sampai lulusan Sarjana, dimana rata-rata pendidikannya setingkat SLTP. Kondisi memberikan indikasi bahwa Bank BRI tidak memberikan persyaratan pendidikan tertentu bagi nasabahnya khususnya nasabah kredit sub sektor perkebunan. Lebih dari setengah responden memiliki motivasi kerja yang rendah. Hal ini dikarenakan orientasi dalam bekerja hanya ditujukan untuk memenuhi kebutuhan keluarga saat ini. Nasabah umumnya belum berorientasi jauh ke depan terutama untuk masa depan anak-anaknya. Jumlah anggota yang masih menjadi tanggungan nasabah adalah 2-3 orang.

Umumnya nasabah sudah mempunyai pengalaman dalam meminjam kredit di Bank BRI yakni 2-3 kali. Mereka menilai bahwa proses peminjaman kreditnya relatif mudah dan bunga yang tidak tinggi, sehingga mereka cenderung meminjam lagi setelah pinjaman sebelumnya terlunasi. Rata-rata agunan yang diberikan nasabah kepada Bank BRI bernilai Rp. 48 juta, yang umumnya berupa sertifikat tanah/kebun. Sementara itu, rata-rata penerimaan nasabah sebesar Rp. 4,1 juta setiap bulannya, dimana penerimaan ini hanya cukup untuk memenuhi kebutuhan setiap bulannya dan kalaupun masih ada sisa jumlahnya hanya sedikit. 
Tabel 1 Karakteristik Responden

\begin{tabular}{|c|c|c|c|c|}
\hline No & Karakteristik & $\%$ & Rata-Rata & Kisaran \\
\hline \multirow[t]{3}{*}{1} & Pendidikan Formal (tahun) & & 8,65 & $4-17$ \\
\hline & Tinggi $(\geq 8,65)$ & 50,72 & & \\
\hline & Rendah $(<8,65)$ & 49,27 & & \\
\hline \multirow[t]{3}{*}{2} & Motivasi & & 3 & $1-6$ \\
\hline & Tinggi $(\geq 3)$ & 42,8 & & \\
\hline & Rendah $(<3)$ & 52,2 & & \\
\hline \multirow[t]{3}{*}{3} & Jumlah Tanggungan Keluarga (org) & & 2,39 & $1-5$ \\
\hline & Banyak $(\geq 2,39)$ & 45 & & \\
\hline & Sedikit $(<2,39)$ & 55 & & \\
\hline \multirow[t]{3}{*}{4} & Pengalaman Pinjaman (tahun) & & & \\
\hline & Berpengalaman $(\geq 2,36)$ & 49,3 & 2,36 & $0,5-8$ \\
\hline & Tdk berpengalaman $(<2,36)$ & 50.7 & & \\
\hline \multirow[t]{3}{*}{5} & Besar Agunan (Rp) & & & \\
\hline & Tinggi ( $\geq 48.347 .826$ jt) & 43,4 & $48.347 .826 \mathrm{jt}$ & $2 \mathrm{jt}-160 \mathrm{jt}$ \\
\hline & $\operatorname{Rendah}(<48.347 .826 \mathrm{jt})$ & 56,6 & & \\
\hline \multirow[t]{3}{*}{6} & Penerimaan (Rp) & & & $2 \mathrm{jt}-8 \mathrm{jt}$ \\
\hline & Tinggi ( $\geq 4.054 .203 \mathrm{jt}$ ) & 36,2 & $4.094 .203 \mathrm{jt}$ & \\
\hline & Rendah $(<4.054 .203 \mathrm{jt})$ & 63,8 & & \\
\hline
\end{tabular}

Sumber: Data primer diolah (2012)

\section{Tingkat Tunggakan Nasabah}

Dalam melakukan pinjaman banyak hal yang mesti diperhatikan oleh pihak bank ataupun pihak calon peminjam agar tidak terjadinya tunggakan. Jika salah satu faktor tidak dapat terpenuhi atau tidak diperhatikan oleh pihak bank dengan demikian ada kemungkinan nasabah dapat melakukan tunggakan. Tunggakan kredit yang dilakukan oleh nasabah akan berbeda satu dengan yang lainnya tergantung dari keadaan sosial dan tujuan yang ingin dicapainya. Untuk lebih jelas dapat dilihat pada Tabel 2.

Berdasarkan hasil penelitian, seperti yang disajikan pada Tabel 2, rata-rata tingkat tunggakan kredit di lokasi penelitian sebesar 53,2 \% dengan kisaran 1 $98 \%$. Hal ini terjadi karena masih ada nasabah yang tidak membayar bunganya dan hanya membayar pinjaman pokoknya setiap sekali angsuran. Nasabah dengan tingkat tunggakan tinggi sebesar 52,2\%, selebihnya 47,8 \% dikategorikan nasabah yang mempunyai tingkat tunggakan kredit rendah. Tingkat tunggakan kredit ini diukur dari besarnya pinjaman dan besarnya angsuran selama pinjaman. Besarnya tingkat tunggakan di daerah penelitian diduga disebabkan adanya penurunan harga produksi pertanian, harga pupuk yang begitu mahal dan sangat langkah sehingga sulit terjangkau oleh nasabah yang mengakibatkan nasabah tidak bisa membayar pinjamannya. 
Tabel 2 Distribusi Nasabah berdasarkan Persentase Tunggakan

\begin{tabular}{clccc}
\hline No & \multicolumn{1}{c}{ Kategori } & $\%$ & Rata-Rata & Kisaran \\
\hline 1 & Tinggi $(\geq 53,2)$ & 52,2 & & \multirow{2}{*}{53,2} \\
2 & Rendah $(<53,2)$ & 47,8 & & $1-98$ \\
\hline
\end{tabular}

Sumber: Data primer diolah (2012)

\section{Faktor-Faktor yang Berkorelasi dengan Tingkat Pengembalian Kredit}

Faktor - faktor yang diduga berkorelasi dengan tingkat tunggakan kredit dapat diketahui dengan menggunakan uji statistik chi-kuadrat $\left(x^{2}\right)$, yang hasil uji statistik disajikan pada Tabel 3.

Tabel 3. Hubungan Antara Variabel Bebas dengan Tingkat Tunggakan Kredit

\begin{tabular}{lcc}
\hline \multicolumn{1}{c}{ Variabel Bebas } & $\begin{array}{c}\text { Chi-Kuadrat } \\
\left(X^{2}\right)\end{array}$ & $\begin{array}{c}\text { Koefisien Kontingensi } \\
(C)\end{array}$ \\
\hline Pendidikan Formal $\left(X_{1}\right)$ & 0,01722 & 0,015 \\
Motivasi $\left(X_{2}\right)$ & $18,42^{*}$ & 0,45 \\
Jumlah Tanggungan Keluarga $\left(X_{3}\right)$ & $27,82^{*}$ & 0,50 \\
Pengalaman Pinjaman $\left(X_{4}\right)$ & $35,1^{*}$ & 0,60 \\
Besar Agunan $\left(X_{5}\right)$ & 2,5 & 0,03 \\
Penerimaan $\left(X_{6}\right)$ & $9,3^{*}$ & 0,34 \\
\hline
\end{tabular}

Sumber: Data primer diolah (2012)

Keterangan : * berhubungan nyata pada tingkat kepercayaan $95 \%\left(\chi^{2}\right.$ hitung $>\chi^{2}$ tabel 3,841)

\section{Pendidikan Formal}

Pendidikan formal merupakan jenjang pendidikan yang ditempuh oleh nasabah responden secara formal mulai dari SD sampai dengan Perguruan Tinggi dan pendidikan formal berfungsi meningkatkan wawasan nasabah serta cara berikir agar dapat mengelola usahataninya dengan baik. Namun kenyataan di lapangan menunjukkan bahwa pendidikan formal tidak berhubungan nyata dengan tingkat tunggakan kredit nasabah. Kesimpulan ini didasarkan pada hasil analisa $\chi^{2}$ dimana nilai $\chi^{2}$ hitung lebih kecil dengan nilai $\chi^{2}$ tabel 3,841 pada taraf kepercayaan 95\%. Kemudian tingkat keeratan hubungan antara dua variabel tersebut tidak erat, dilihat dari nilai koefisien kontingensi $(C=0,015)$. Hal ini dikarenakan tinggi rendahnya tingkat tunggakan kredit nasabah tidak ditentukan oleh tinggi rendahnya tingkat pendidikan nasabah yang didapatkan. Argumennya, pendidikan formal secara teknis tidak menjelaskan dan menerangkan secara rinci bagaimana suatu kegiatan tunggakan dimulai, diproses sampai mendapatkan hasil produksi sehingga petani tidak 
mendapatkan pengetahuan secara teknis melalui proses pendidikan formal. Hasil penelitian ini juga sama dengan hasil penelitian Tribowo (2009). Tribowo menemukan bahwa tidak ada hubungan yang nyata antara pendidikan formal dengan tingkat tunggakan kredit. Namun demikian bertolak belakang dengan hasil penelitian Alamsyah (2007), yang menyatakan bahwa pendidikan formal berhubungan nyata dengan tingkat tunggakan kupedes sektor agribisnis BRI unit Ciomas.

\section{Motivasi Nasabah}

Variabel motivasi diduga berhubungan dengan tingkat tingkat tunggakan nasabah, karena motivasi berkaitan dengan tindakan seseorang dalam mengambil keputusan. Semakin tinggi tingkat motivasinya maka semakin rendah kemungkinan akan terjadinya tunggakan. Hipotesa ini dapat diterima secara statistik yang ditujukkan dari hasil uji korealasi dengan analisa chikuadrat $\left(\chi^{2}\right)$. Nilai $\chi^{2}$ hitung lebih besar dengan nilai $\chi^{2}$ tabel, seperti yang ditunjukkan pada Tabel 3 di atas. Hasil uji ini menginformasikan bahwa motivasi berhubungan nyata dengan tingkat tunggakan kredit nasabah. Tingkat keeratan hubungan antara dua variabel tersebut cukup erat, dilihat dari nilai koefisien kontingensi $(C=0,45)$. Ini berarti bahwa semakin tinggi motivasi, maka semakin rendah tingkat tunggakan kredit nasabah. Temuan ini sejalan dengan hasil penelitian Suharynto dan Wiguna (2003), menyatakan bahwa motivasi berhubungan nyata dengan tingkat penyebab terjadinya tunggakan kredit program P4K yang diambil kelompok petani kecil di Propinsi Bali.

\section{Jumlah Tanggungan Keluarga}

Hasil analisa chi-kuadrat $\left(\chi^{2}\right)$ menunjukkan nilai $\chi^{2}$ hitung lebih besar dengan nilai $\chi^{2}$ tabel 3,841 pada taraf kepercayaan $95 \%$. Ini berarti, hipotesis yang menyatakan bahwa jumlah tanggungan keluarga tidak berkorelasi dengan tingkat tunggakan harus ditolak. Nilai koefisien kontingensi $(C=0,5)$ juga mengindikasikan keeratan korelasi antara 2 variabel ini. Dengan demikian, semakin banyak jumlah tanggungan keluarga, maka semakin tinggi tingkat tunggakan kredit nasabah. Armumentasi yang dapat menjelaskan temuan ini adalah adanya jumlah keluarga yang tinggi berimbas pada banyaknya pengeluaran yang harus ditanggung oleh kepala rumah tangga, sehingga mempengaruhi pola pembayaran tiap bulannya. Hasil ini sejalan dengan hasil penelitian Triwibowo (2009) yang menyimpulkan bahwa jumlah tanggungan keluarga berhubungan nyata dengan tingkat pengembalian kredit BPR Rama Ganda Bogor. Hasil penelitian lain yang sejalan adalah penelitian Asih (2007). Asih menemukan bahwa terdapat hubungan nyata antara jumlah tanggungan keluarga dengan tingkat pengembalian kredit. Dengan tanggungan keluarga yang lebih banyak, seseorang akan membutuhkan biaya hidup yang semakin tinggi guna memenuhi kebutuhan keluarganya. Untuk itu, rumah tangga harus memperoleh penghasilan yang besar. Hal ini akan di dapat jika mereka bekerja 
dengan motivasi kerja yang tinggi dan memanfaatkan waktu sebaik mungkin dalam bekerja sehingga upah yang mereka terima juga akan lebih tinggi.

\section{Pengalaman Pinjaman}

Variabel pengalaman pinjaman nasabah berhubungan nyata dengan tingkat tunggakan kredit nasabah. Kesimpulan ini didasrkan dari hasil analisa chi-kuadrat $\left(\chi^{2}\right)$ menunjukkan nilai $\chi^{2}$ hitung lebih besar dengan nilai $\chi^{2}$ tabel 3,841 pada taraf kepercayaan $95 \%$, sehingga hipotesis yang dihasilkan adalah terima $\mathrm{H}_{1 .}$. Hasil uji tingkat keeratan hubungan antara dua variabel tersebut erat yang ditunjukkan dari nilai koefisien kontingensi $(C=0,6)$. Lamanya pengalaman pinjaman nasabah mempengaruhi pola pikir nasabah untuk dapat membayar tepat waktu. Lamanya mereka menjadi nasabah sehingga membuat mereka untuk tetap menjaga hubungan baik dengan pihak bank dengan cara membayar kredit dengan tepat waktu. Hasil penelitian ini sejalan dengan hasil penelitian Triwibowo (2009), yang menyatakan bahwa pengalaman pinjaman nasabah berhubungan nyata dengan tingkat pengembalian kredit BPR Rama Ganda Bogor

\section{Besar Agunan}

Hasil analisa chi-kuadrat $\left(X^{2}\right)$ menunjukkan nilai $\chi^{2}$ hitung lebih kecil dibandingkan dengan nilai $\chi^{2}$ tabel $(3,841)$ pada taraf kepercayaan $95 \%$. Analisa tingkat keeratan juga menunjukkan ketidak eratan hubungan antara dua variabel besar agunan dengan tingkat pengembalian yang dilihat dari nilai koefisien kontingensi $(\mathrm{C}=0,03)$ Dengan demikian, hipotesis nihil $\left(\mathrm{H}_{0}\right)$ diterima dan $\left(\mathrm{H}_{1}\right)$ ditolak, yang berarti besar agunan tidak berhubungan nyata dengan tingkat tingkat tunggakan kredit. Selanjutnya dapat diartikan bahwa rendahnya jumlah agunan tetap terjadi tunggakan kredit. Hal ini dikarenakan tinggi rendahnya tingkat tunggakan kredit nasabah tidak ditentukan oleh tinggi rendahnya jumlah agunan nasabah yang didapatkan. Besarnya agunan hanya menjadi syarat untuk dapat mengajukan pinjaman sesuai dengan dana yang dibutuhkan. Temuan ini juga sesuai dengan hasil penelitian Triwibowo, D. (2009) tentang terjadinya ketidak adanya hubungan nyata antara besar agunan dengan tingkat tunggakan kredit. Namun, temuan ini berbanding terbalik dengan hasil penelitian Junaidi dan Bachtiar (2010).

\section{Penerimaan Kepala Keluarga}

Penerimaan diduga berhubungan nyata dengan tingkat tunggakan kredit nasabah, karena berhubungan dengan keahlian nasabah dalam mengelola pinjaman. Dari penerimaan memungkinkan nasabah untuk membayar pinjamannnya bagaimana cara meningkatkan atau memanfaatkan pinjaman dengan baik. Hasil analisa chi-kuadrat $\left(\chi^{2}\right)$ menunjukkan nilai $\chi^{2}$ hitung lebih besar dengan nilai $\chi^{2}$ tabel 3,841 pada taraf kepercayaan $95 \%$, sehingga hipotesis 
yang dihasilkan yaitu terima $\mathrm{H}_{1}$. Artinya, variabel penerimaan nasabah berhubungan nyata dengan tingkat tunggakan kredit nasabah. Tingkat keeratan hubungan antara dua variabel ini cukup erat, dilihat dari nilai koefisien kontingensi $(C=0,34)$. Menurut Rachmat dan Maya (2004), dengan adanya penerimaan yang besar maka memudahkan nasabah dalam menghindari terjadinya tunggakan. Hasil penelitian ini sejalan dengan hasil penelitian Asih (2007), yang menyatakan bahwa penerimaan nasabah berhubungan nyata dengan tingkat pengembalian kredit pengusaha kecil pada program kemitraan.

\section{SIMPULAN DAN SARAN}

\section{Simpulan}

Berdasarkan hasil penelitian dan pembahasan yang telah dilakukan maka dapat ditarik kesimpulan sebagai berikut: (a) Sebagian nasabah mempunyai tunggakan kredit dengan kategori tinggi, dan (b) Faktor-faktor yang berhubungan nyata dengan tingkat tunggakan kredit nasabah adalah motivasi, jumlah tanggungan keluarga, pengalaman pinjaman, dan penerimaan Kepala Keluarga

\section{Saran}

Berkaitan dengan terjadinya kredit bermasalah pada sektor pertanian yang disebabkan oleh faktor motivasi, jumlah tanggungan keluarga, pengalaman pengambilan kredit, dan pemerimaan di PT. BRI Unit Pasar Rengas Provinsi Jambi disarankan untuk menggunakan jumlah anggota keluarga sebagai salah satu indikator atau kriteria sebagai salah satu persyaratan untuk memperoleh kredit. Selain itu pihak BRI perlu menggali informasi lebih mendalam tentang kejujuran pengisian aplikasi awal calon debitur, watak kepribadian calon debitur, misalnya berkelakuan baik, jujur serta mempunyai reputasi yang baik. Informasi tersebut dapat diperoleh dari crosscheck masyarakat, ketua RT/RW serta pejabat daerah setempat.

Terkait pengalaman pengambilan kredit dan motivasi nasabah,pihak BRI dapat memberikan program khusus kepada debitur yang lancar dalam pengembalian kredit agar mendapatkan tambahan dana lagi dengan memperpanjang masa tenor kreditnya (Top Up) serta menawarkan kembali pinjaman kepada pihak debitur yang sudah lunas, karena mereka sudah mengetahui aturan main dalam peminjaman dan pembayaran kredit sehingga memotivasi mereka untuk terus setia kepada PT. BRI. 


\section{DAFTAR PUSTAKA}

Alamsyah, T. 2007. Analisis Faktor-faktor yang Mempengaruhi Tingkat Pengembalian Kredit Usaha Pedesaan (Kupedes) Sektor Agribisnis (BRI Unit Ciomas). [Skripsi]. Program Ekstensi Manajemen Agribisnis. Fakultas Pertanian. Institut Pertanian Bogor.

Asih, M. 2007. Analisis Faktor-Faktor yang Mempengaruhi Pengembalian Kredit PengusahaPada Program Kemitraan Corporate Social Responsibility ( Studi Kasus: PT. Telkom Divre II Jakarta)). [Skripsi]. Program Ilmu Ekonomi. Fakultas Ekonomi dan Manajemen. Institut Pertanian Bogor

[BPS]. 2000. Jambi dalam Angka. Badan Pusat Statistik Prov. Jambi.

Kasmir. 2002. Bank dan Lembaga Keuangan lainnya. Jakarta: PT. Grafindo Persada.

Nuhung, I.A. 2000. Reorientasi Pembangunan Pertanian Dan Peran Perguruan Tinggi Pertanian: Suatu Pembahasan. Kumpulan Makalah Utama Dalam Seminar Nasional Hasil Penelitian. Bengkulu: Fakultas Pertanian Univeersitas Bengkulu, 23-24 Oktober 2000, hal 1-2

Racmat, F dan Maya, A. 2004. Manajemen Pengkreditan Bank Umum: Teori Masalah, Kebijakan dan Aplikasinya Lengkap Serta Analisis Kredit. Alfabeta. Bandung.

Siegel, S. 1992. Statistik Non Parametrik. PT Gramedia Pustaka Utama, Jakarta. Sinungun. 1987. Produktivitas Apa dan Bagaimana. PT. Bina Aksara, Jakarta.

Suhayanto, dan Wiguna A. 2003. Pemanfaatan Kredit dan Faktor-Faktir Penyebab Terjadinya Tunggakan Kredit Program P4K yang Diambil

Kelompok Petani Kecil (KPK) di Propinsi Bali. Jurnal Balai Pengkajian Teknologi Pertanian (BPTP). Bali (01-03-2011)

Syafri, 2003. Analisis Kredit Perbankan 1997-2002 ; Pendekatan Kointegrasi dan Model Koresksi Kesalahan. Jakarta ; Pusat Pengkajian dan Pelayanan Informasi $\left(\mathrm{P}_{3} \mathrm{I}\right)$ Sekretariat Jendral DPR RI

Triwibowo, D . 2009. Analisis Faktor-Faktor yang Mempengaruhi Pengambilan Kredit Bermasalah Oleh Nasabah di Sektor Perdagangan Agribisnis, Kasus Pada BPR Rama Ganda [Skripsi]. Program Ekstensi Manajemen Agribisnis. Fakultas Pertanian. Institut Pertanian Bogor. 